\title{
A new Geoengineering Model Intercomparison Project (GeoMIP) experiment designed for climate and chemistry models
}

\author{
S. Tilmes ${ }^{1}$, M. J. Mills ${ }^{1}$, U. Niemeier ${ }^{2}$, H. Schmidt ${ }^{2}$, A. Robock ${ }^{3}$, B. Kravitz ${ }^{4}$, J.-F. Lamarque ${ }^{1}$, G. Pitari ${ }^{5}$, and \\ J. M. English 6 \\ ${ }^{1}$ National Center for Atmospheric Research, Boulder, Colorado, USA \\ ${ }^{2}$ Max Planck Institute for Meteorology, Hamburg, Germany \\ ${ }^{3}$ Department of Environmental Sciences, Rutgers University, New Brunswick, New Jersey, USA \\ ${ }^{4}$ Pacific Northwest National Laboratory, Richland, Washington, USA \\ ${ }^{5}$ Department of Physical and Chemical Sciences, Università L'Aquila, 67010 Coppito, L'Aquila, Italy \\ ${ }^{6}$ University of Colorado at Boulder, Boulder, Colorado, USA
}

Correspondence to: S. Tilmes (tilmes@ucar.edu)

Received: 12 July 2014 - Published in Geosci. Model Dev. Discuss.: 12 August 2014

Revised: 8 December 2014 - Accepted: 9 December 2014 - Published: 15 January 2015

\begin{abstract}
A new Geoengineering Model Intercomparison Project (GeoMIP) experiment "G4 specified stratospheric aerosols" (short name: G4SSA) is proposed to investigate the impact of stratospheric aerosol geoengineering on atmosphere, chemistry, dynamics, climate, and the environment. In contrast to the earlier G4 GeoMIP experiment, which requires an emission of sulfur dioxide $\left(\mathrm{SO}_{2}\right)$ into the model, a prescribed aerosol forcing file is provided to the community, to be consistently applied to future model experiments between 2020 and 2100. This stratospheric aerosol distribution, with a total burden of about $2 \mathrm{TgS}$ has been derived using the ECHAM5-HAM microphysical model, based on a continuous annual tropical emission of $8 \mathrm{Tg} \mathrm{SO}_{2} \mathrm{yr}^{-1}$. A ramp-up of geoengineering in 2020 and a ramp-down in 2070 over a period of 2 years are included in the distribution, while a background aerosol burden should be used for the last 3 decades of the experiment. The performance of this experiment using climate and chemistry models in a multi-model comparison framework will allow us to better understand the impact of geoengineering and its abrupt termination after 50 years in a changing environment. The zonal and monthly mean stratospheric aerosol input data set is available at https://www2.acd.ucar.edu/gcm/ geomip-g4-specified-stratospheric-aerosol-data-set.
\end{abstract}

\section{Introduction}

The Geoengineering Model Intercomparison Project (GeoMIP) has been successful in investigating the impact of large-scale geoengineering on various climate parameters, including global and regional temperature and precipitation, the energy budget, sea ice, climate extremes, and crop production (e.g., Kravitz et al., 2013a, b; Special Section on GeoMIP, 2014). GeoMIP includes four model experiments designed to calculate the response of the climate system to large-scale solar radiation management (SRM) techniques while offsetting anthropogenic greenhouse warming (Kravitz et al., 2011). The G1 experiment involves reduction of incoming solar radiation to counteract a radiative forcing of 4 times the amount of carbon dioxide $\left(\mathrm{CO}_{2}\right)$ relative to preindustrial control conditions. The $\mathrm{G} 2$ experiment involves the same solar dimming technique to offset a gradual increase in $\mathrm{CO}_{2}$ from pre-industrial levels. Calculations indicate that, relative to pre-industrial conditions, solar dimming of this scale would result in a slow-down of the hydrological cycle (Tilmes et al., 2013), a reduced, but continued warming of the high latitudes (Schmidt et al., 2012; Kravitz et al., 2013a), a reduction in sea ice (Moore et al., 2014), and a reduction of agricultural production (Xia et al., 2014). Further, SRM reduces extreme temperature and precipitation changes in comparison to a non-geoengineering scenario with 4 times the $\mathrm{CO}_{2}$ (Curry et al., 2014). 
The other two GeoMIP experiments, G3 and G4, require the enhancement of stratospheric sulfate aerosols due to the continuous emission of sulfur dioxide $\left(\mathrm{SO}_{2}\right)$ into the tropical lower stratosphere for the period 2020 and 2070, using the Representation Concentration Pathway 4.5 (RCP4.5) Coupled Model Intercomparison Project Phase 5 (CMIP5) future projection (Taylor et al., 2012). G4 requires the emission of $5 \mathrm{Tg}$ of $\mathrm{SO}_{2}$ each year on the Equator, while $\mathrm{G} 3$ requires counteracting the anthropogenic radiative forcing of the RCP4.5 future projection between 2020 and 2070 by increasing the emission rate of $\mathrm{SO}_{2}$ accordingly (Kravitz et al., 2011). The impact of sulfate aerosols could be different from solar dimming experiments. Both would decrease the shortwave incoming radiation. However, stratospheric aerosols heat the stratosphere, which changes the dynamics of the atmosphere and the radiative response. In particular, a stronger slow-down of the hydrological cycle was found for the aerosol-based methods as compared to the solar constant reduction (Ferraro et al., 2014; Niemeier et al., 2013). A recent study by Aquila et al. (2014) identifies significant changes in the Quasi-Biennial Oscillation (QBO), with a prolongation of the $\mathrm{QBO}$ westerly phase at $50 \mathrm{hPa}$, if geoengineering with stratospheric aerosols were to be applied. Further, enhanced aerosols change stratospheric chemistry and therefore ozone (e.g., Tilmes et al., 2009).

So far, only a limited number of models have performed the G3 and G4 GeoMIP experiments. The G3 experiment has turned out to be especially difficult to perform, since it is not straightforward to determine the changing rate of $\mathrm{SO}_{2}$ emissions required to counteract the anthropogenic radiative forcing in the future scenario. Furthermore, not many models have the ability to perform prognostic aerosol experiments including detailed aerosol microphysics. As shown by Heckendorn et al. (2009), Niemeier et al. (2011), and English et al. (2012), aerosol mass and properties significantly change with increasing emission rates, which has to be taken into account. Since GeoMIP was designed to build on CMIP5, most of the models did not include interactive chemistry and hence some potentially important coupling effects are missing. The models that performed G3 and G4 experiments derived very different stratospheric aerosol distributions, due to different assumptions of aerosol properties and differences in stratospheric transport and heating rates of the models (Berdahl et al., 2014; Pitari et al., 2014). Some models maintain a large burden of mass in the tropics, while others produce a maximum in higher latitudes. Those differences result in very different lifetimes of stratospheric aerosols and therefore differences in the required emission rate for the different models. The change in net tropopause radiative forcing of available experiments ranges between -0.74 and $-1.54 \mathrm{~W} \mathrm{~m}^{-2}$ (Pitari et al., 2014), which limits the identification of robust climate impacts of geoengineering. Furthermore, the lack of comprehensive tropospheric and stratospheric chemistry in most models neglects the chemistry radiation coupling (mostly via ozone), which can be important for climate impacts.
Investigating differences in aerosol distribution due to sulfur injection as simulated by different models may be important for studies examining the rate and spatial pattern of emissions, and subsequent distribution by interaction with model dynamics. We propose a new GeoMIP experiment that uses a uniformly prescribed stratospheric aerosol distribution to address the dependence of the different parameterizations in fully coupled chemistry and climate models and the impact of future climate change. By constraining the prescribed stratospheric aerosol distribution, we reduce the degrees of freedom from earlier model comparisons of G4, which will reduce the spread of the responses and help identify key sources of uncertainties in the chemical, dynamical, and radiative response to geoengineering with stratospheric sulfate aerosols. Other applications of the stratospheric aerosol distribution may include comparisons to distributions of interactive microphysical models, which include different feedbacks.

\section{Experimental design}

The design of the new GeoMIP experiment G4SSA (specified stratospheric aerosols) is similar to the GeoMIP G4 experiment (Kravitz et al., 2011), but defines a fixed prescribed stratospheric aerosol distribution between years 2020 and 2070 , instead of requiring the emission of $\mathrm{SO}_{2}$. The baseline simulation uses the RCP6.0 CMIP5 future projection (Taylor et al., 2012), as discussed below (Fig. 1, top panel). A different baseline scenario could be considered as well, for instance RCP4.5, which is used for the original GeoMIP G3 and G4 experiments and describes a very similar forcing in comparison to the RCP6.0 between 2020 and 2070. Even simpler experiments, like time-slice experiments for different climate and chemistry conditions, could be used to investigate the impact of changes to stratospheric aerosol loading.

The stratospheric sulfur burden of about $2 \mathrm{Tg} \mathrm{S}$ in the form of sulfate was derived from the emission of $8 \mathrm{Tg} \mathrm{SO}_{2}$ per year for 2 years until a steady-state distribution was reached (Fig. 1, bottom panel). The burden has a larger radiative forcing than the original GeoMIP G4 experiment and will therefore lead to more robust deviations of climate variables from a baseline experiment than using a smaller emission case. A larger forcing has also a more pronounced impact on stratospheric dynamics, in particular the QBO (Aquila et al., 2014). The derived stratospheric sulfur burden of about $2 \mathrm{Tg} \mathrm{S}$ counteracts the total anthropogenic radiative forcing of about $-1.1 \mathrm{~W} \mathrm{~m}^{-2}$ based on earlier model studies using ECHAM6 (Niemeier et al., 2013) and about $-1.5 \mathrm{~W} \mathrm{~m}^{-2}$, based on the Community Earth System Model (CESM) (not shown), but may further vary between different models.

Microphysical model studies have shown that the most efficient reduction of the radiative forcing occurs for small emission rates into background conditions (Heckendorn et al., 2009; Niemeier et al., 2011; English et al., 2012). 

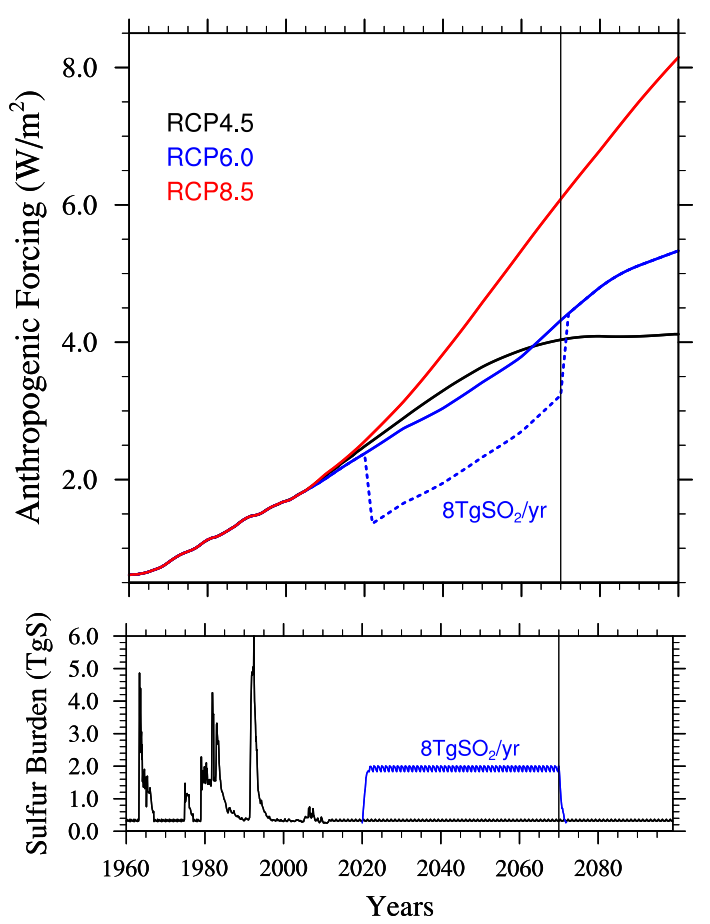

Figure 1. Top panel: total anthropogenic radiative forcing of the CMIP5 model experiments RCP4.5 (black), RCP6.0 (blue), and RCP8.5 (red) (Meinshausen et al., 2011). The dashed line indicates the radiative forcing of the GeoMIP experiment for CCMI, using a prescribed aerosol distribution assuming an emission of $8 \mathrm{Tg} \mathrm{SO}_{2}$ per year. The amount of radiative forcing reduction due to the enhanced aerosol burden is estimated based on the ECHAM5-HAM model (see text). Bottom panel: sulfur burden in $\mathrm{Tg} \mathrm{S}$ (in the form of $\mathrm{H}_{2} \mathrm{SO}_{4}$ ) per year, based in the CCMI prescribed aerosol data set (black) and the new GeoMIP experiment data set (blue), based on $8 \mathrm{Tg} \mathrm{SO}_{2}$ emission per year case.

Larger burden of aerosols reduces the efficiency of additional aerosols to increase the planetary albedo. This is because large burdens of aerosol particles coagulate faster to form larger particles, which are less reflective per unit mass, and shorter-lived due to faster sedimentation. This reveals important limitations of stratospheric aerosol geoengineering (see Table 1). Table 1 is based on a specific climate model, and the results will vary between different models. In the experiment proposed here, we assume a fixed aerosol emission rate per year, which allows the use of a monthly varying steadystate aerosol forcing file for the entire period, except for the ramp-up and ramp-down periods (see below).

The aerosol distribution for this experiment is derived using the middle atmosphere version of the general circulation model ECHAM5 (Roeckner et al., 2003) interactively coupled to a modified version of the aerosol microphysical model HAM (Stier et al., 2005). HAM calculates the formation of sulfate aerosol, which includes nucleation, accumulation, condensation, and coagulation processes. Aerosol size is determined using the M7 modal aerosol module (Vi-
Table 1. Global average radiative forcing from a stratospheric sulfate aerosol cloud needed to counteract the anthropogenic radiative forcing from the RCP8.5 scenario (Niemeier et al., 2013). The third column shows the stratospheric aerosol emission rate per year required to produce this radiative forcing, in $\mathrm{Tg} \mathrm{SO}_{2} \mathrm{yr}^{-1}$, although the aerosols are sulfuric acid droplets. The rapidly increasing burden to counteract radiative forcing illustrates the disproportionate increase in sulfur emissions of greater than $2 \mathrm{~W} \mathrm{~m}^{-2}$ due to effects of aerosol growth and removal processes and therefore demonstrates the limitations of stratospheric aerosol geoengineering. The uncertainty of these values drastically increases with increasing emission values larger than $10 \mathrm{Tg} \mathrm{SO}_{2}$ per year.

\begin{tabular}{crr}
\hline Year & $\mathrm{W} \mathrm{m}^{-2}$ & $\mathrm{Tg} \mathrm{SO}_{2}$ per year \\
\hline 2020.0 & 0 & 0.0 \\
2023.9 & 0.21 & 1.0 \\
2026.2 & 0.35 & 2.0 \\
2030.9 & 0.63 & 4.0 \\
2034.4 & 0.86 & 6.0 \\
2037.5 & 1.09 & 8.0 \\
2041.4 & 1.36 & 10.0 \\
2044.6 & 1.535 & 12.0 \\
2048.5 & 1.84 & 16.0 \\
2054.0 & 2.33 & 20.0 \\
2070.0 & 3.60 & 40.0 \\
2086.2 & 4.69 & 60.0 \\
2099.0 & 5.53 & 80.0 \\
\hline
\end{tabular}

gnati, 2004), which calculates the aerosol size distribution using seven lognormal modes of prescribed standard deviation $(\sigma)$. M7 was modified to allow for a better representation of stratospheric sulfur aerosol according to box-model studies (Kokkola et al., 2009) and previous geoengineering studies (Heckendorn et al., 2009). The changes include a smaller standard deviation $(\sigma)$ of the coagulation mode (1.2 instead of 1.59) as the value of $\sigma$ determines the development of the size distribution. The simulation includes only sulfate aerosol. Besides the geoengineered sulfur, only dimethyl sulfide (DMS) and carbonyl sulfide (OCS) emissions are included in this setup and no anthropogenic emissions are assumed for the background (Niemeier et al., 2009). A total of $8 \mathrm{Tg}$ of $\mathrm{SO}_{2}$ per year are emitted into a single grid box, $2.8 \times 2.8$ degrees in size, and located at a height of $60 \mathrm{hPa}$ at the Equator. Further details on the model setup and the results are given by Niemeier et al. (2011).

The same model setup has also been used for simulations of the evolution of a sulfuric cloud after a volcanic eruption and was carefully tested against measurements taken after the 1991 Mt. Pinatubo eruption (Niemeier et al., 2009; Toohey et al., 2011). The results show a good representation of the particle size and the global aerosol load. The modeled global aerosol load decreases faster than the measurements 1 year after the eruption. This is probably related to the particle size being in the upper range of the measurements and a slight overestimation of the poleward trans- 
port. The global distribution of the aerosols compares well to the updated time series by Sato et al. (1993, with update retrieved from http://data.giss.nasa.gov/modelforce/strataer), especially in the Southern Hemisphere, but it shows an overestimation in the first months after the eruption and a shorter lifetime of the volcanic cloud within the tropics. Top-of-theatmosphere shortwave radiative fluxes compare very well to observations by the Earth Radiation Budget Experiment (Toohey et al., 2011), and we conclude that the transport of the aerosols into both hemispheres is well represented by the model based on observations. This model does not simulate a QBO and rather has a steady easterly phase of the QBO.

The aerosol distribution resulting from an $8 \mathrm{Tg} \mathrm{SO}_{2}$ emission per year experiment would be different from a distribution of a single volcanic eruption, as shown in Fig. 2. Our calculated geoengineered aerosol distribution has higher surface area densities (SAD) than the Chemistry Climate Model Initiative (CCMI) stratospheric aerosol data for the year 1992, based on Stratospheric Aerosol and Gas Experiment (SAGE) II V6 satellite observations (Eyring et al., 2013), especially in the middle and high latitudes. This is due to the long-term emission of aerosols and because the CCMI data set is averaged over a period where aerosols are already decaying. Also SAD and the aerosol burden are likely underestimated in the CCMI Pinatubo data set in high latitudes due to the lack of observational information and interpolation issues.

The prescribed aerosol distribution ramps up in the first 2 years and down in the last 2 years, consistent with the assumption that geoengineering is started and stopped abruptly. This will enable the response of the atmosphere and ocean in the first few years following the start of geoengineering to be compared to the response of the climate system to a volcanic eruption with a one-off emission of a certain aerosol burden. Also, after termination of geoengineering, the simulations will be continued over the years 2070-2100, allowing the adjustment of the atmosphere and climate after a longterm application of aerosol loading to be compared to a shortterm imposition of the radiative forcing following a volcanic eruption

Due to the importance of stratospheric aerosols on radiation, chemistry, and dynamics, the proposed experiment is well suited to be coordinated with the CCMI efforts. Models engaged in CCMI include a comprehensive description of stratospheric and in part tropospheric chemistry. The CCMIdefined core future experiment for chemistry-climate models is the REF-C2 experiment, covering the period 1960 and 2100 and following the RCP6.0 CMIP5 future projection (Eyring et al., 2013). REF-C2 includes only background stratospheric aerosols, without the inclusion of potential future volcanic eruptions, and therefore it serves well as a baseline for the proposed GeoMIP experiment. REF-C2 is designed to be fully coupled using a dynamic ocean and sea ice to allow interactions between changes in chemistry and climate and, if possible, to produce an interactive QBO.

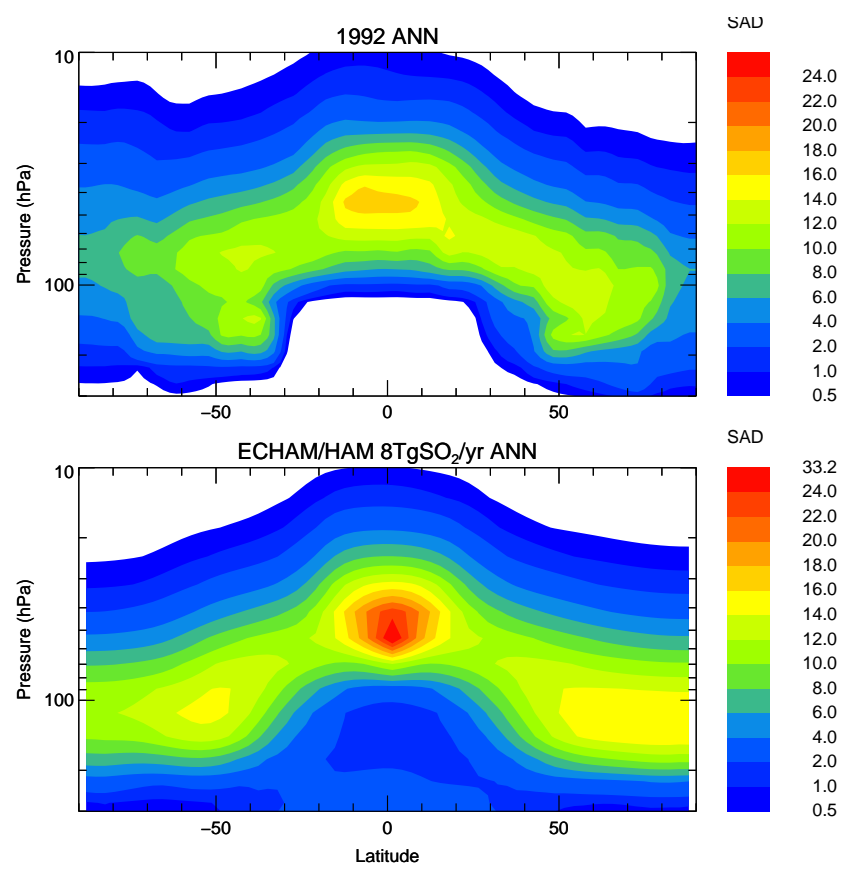

Figure 2. Top panel: 1992 annual average surface area density (SAD) distribution in $\mu \mathrm{m}^{2} \mathrm{~cm}^{-3}$ derived using the CCMI stratospheric aerosol data set (Eyring et al., 2013), following the $1991 \mathrm{Mt}$. Pinatubo volcanic eruption. Bottom panel: steady-state prescribed aerosol distribution of the proposed GeoMIP experiment, based on a $8 \mathrm{Tg} \mathrm{SO}_{2} \mathrm{yr}^{-1}$ emission scenario using the ECHAM5-HAM model (Niemeier et al., 2013).

To perform G4SSA, the background aerosol forcing file should be replaced between 2020 and 2071 with the GeoMIP-prescribed aerosols forcing file provided to the community. The zonal and monthly mean stratospheric aerosol input data set is available at https://www2.acd.ucar.edu/gcm/ geomip-g4-specified-stratospheric-aerosol-data-set. It includes mass and aerosol properties, and optical depth at $550 \mathrm{~nm}$ wavelength on vertical pressure levels. As for the CCMI aerosol forcing file, we recommend removing the prescribed stratospheric aerosols below the model tropopause, because tropospheric aerosols are included separately in the models.

\section{Scientific questions that can be addressed with the proposed experiment}

A variety of impacts of stratospheric aerosol geoengineering have been proposed, including changes in ozone and ultraviolet radiation (UV) (Tilmes et al., 2012; Pitari et al., 2014), stratospheric chemistry and dynamics (e.g., Tilmes et al., 2009; Heckendorn et al., 2009; English et al., 2012), impacts on the QBO (Aquila et al., 2014), and changes of the Hadley circulation (Niemeier et al., 2013). 
Increased SAD due to the enhanced aerosol burden results in increased heterogeneous reactions. In high latitudes, this would result in significantly more ozone depletion. In middle and low latitudes, column ozone changes strongly depending on the stratospheric halogen burden, which should decrease through the 21 st century due to international agreements limiting ozone-depleting substances. Pitari et al. (2014) compared four models and found that geoengineering would deplete global stratospheric ozone until the middle of this century, after which it would increase. Tilmes et al. (2012) discussed the importance of very short-lived halogen components included in the models for quantifying the effects of geoengineering on ozone and erythemal UV. Tropospheric chemistry may be further impacted by the change in stratospheric aerosol burden. The change in ozone column as well as the scatter of aerosols changes the amount of UV reaching the troposphere, which likely impacts the tropospheric chemical composition and the lifetimes of major gases.

Sulfate aerosols affect stratospheric dynamics (Robock, 2000). These impacts are only felt for 1 or 2 years following a large tropical volcanic eruption, depending on the latitudinal distribution of the aerosols and the phase of the QBO (Trepte and Hitchman, 1992). The radiative heating of stratospheric aerosols impacts the Brewer-Dobson circulation (BDC), the vertical velocity in the tropics, and with it the chemical distribution of the stratosphere (Heckendorn et al., 2009; Tilmes et al., 2009). Stratospheric circulation changes may further impact upper troposphere-lower stratosphere exchange processes. Potential changes in the QBO may have additional significant impacts on stratospheric dynamics with impacts on climate (Aquila et al., 2014). Changes in column ozone, especially in high latitudes, also impact tropospheric circulation and the Southern Annual Mode (e.g., Thompson et al., 2011). The quantification of those changes as a result of geoengineering and their impact on surface climate, agriculture and other impacts can be investigated by performing the proposed experiment within a coordinated multi-model comparison study.

Other important effects cannot be investigated in the proposed experiment, since the stratospheric aerosol distribution is prescribed. This includes interactions between the aerosol composition, the dynamics, and transport of stratospheric aerosols into the troposphere, which may influence cloud properties and with this precipitation, as well as tropospheric heterogeneous reactions.

\section{Summary and conclusions}

A new GeoMIP experiment "G4 specified stratospheric aerosols" (G4SSA) is proposed, using a prescribed stratospheric aerosol distribution to estimate the impact of a $2 \mathrm{Tg} \mathrm{S}$ aerosol burden between 2020 and 2071 (including a 2-year ramp-down period) in climate and chemistry models. This burden is the result of a continuous tropical emission of
$8 \mathrm{Tg} \mathrm{SO}_{2}$ per year based on microphysical model calculations. Differences in the chemical, dynamical, and climate response between the baseline simulation and the geoengineering simulation can be investigated between the years 2030 and 2069, after the adjustment of the atmosphere and the upper ocean. The impact of an abrupt termination of geoengineering can be investigated in the years between 2070 and 2100.

The following scientific questions may be addressed with the proposed geoengineering experiment, especially if performed in a multi-model framework like CCMI: what are the impacts of geoengineered stratospheric aerosols and the termination of geoengineering on chemical composition, dynamics, and climate, in a changing future environment on

- stratospheric chemistry, in particular ozone and its impact on UV?

- tropospheric ozone and methane lifetime?

- stratospheric dynamics, including stratospheric heating rates, $\mathrm{BDC}$, and $\mathrm{QBO}$ ?

- tropospheric dynamics and temperatures?

- climate, surface temperatures and precipitation?

- environmental impacts and agriculture?

To address the different science questions, specific capabilities of models are required. Changes in tropospheric dynamics, temperatures, and precipitation can be investigated based on model results from all GCMs (Global Climate Models), some of which may not include comprehensive chemistry. In addition, most of the CCMI models are expected to be able to simulate interactions between and increased aerosol layer in the stratosphere, stratospheric chemistry and dynamics, including changes of heating rates and the BDC, as is the case when simulating past volcanic eruptions. An offline UV model may be required to identify the impact on surface UV, as done by Tilmes et al. (2012). The impact of geoengineering on the QBO can only be investigated if models produce the QBO interactively, which may not be the case for any participating CCMI models. However, applying this experiment to other GCMs may allow producing results to investigate this question. The results from models that simulate tropospheric chemistry can be used to identify the impact on tropospheric ozone and methane lifetime. Differences in the impact on methane lifetime will occur whether models prescribe methane concentrations at the surface, which is likely the case, or they emit methane. Finally, changes in agriculture and the environment due to geoengineering may not be addressed directly from any model output at this time, but offline model simulations using crop models can be applied to investigate the impacts of geoengineering (e.g., Xia et al., 2014). 
The proposed GeoMIP experiment is not intended to suggest a realistic geoengineering scenario, but is aimed at identifying potential changes to the climate system as a result of a long-term stratospheric aerosol forcing and an abrupt removal of this forcing. The use of a different microphysical model for deriving the prescribed aerosol burden, or different assumptions of aerosol properties and emission strategies, may result in very different aerosol distributions (Pitari et al., 2014; Niemeier et al., 2011; English et al., 2012). For instance, the injection in a latitude band of 10 or $20^{\circ}$ around the Equator instead of right at the Equator would result in a larger spread of aerosols into mid-latitudes (English et al., 2012; Pierce et al., 2010). However, the ECHAM5-HAM model tends to overestimate the transport into high latitudes and therefore may shift the aerosols too far towards the poles. Comprehensive microphysical simulations that include interactions between chemistry, clouds, dynamics and radiation are not available to date. Furthermore, geoengineering observations are not available to evaluate the models, and observations after volcanic eruptions, like Mt. Pinatubo, only cover size distributions up to $0.6-0.7 \mu \mathrm{m}$. More work is needed to evaluate different microphysical models and differences of different emission schemes. Nevertheless, a multi-model comparison of chemistry-climate models using the same prescribed aerosol distribution would be of great relevance for the estimation of the effectiveness and risk of proposed climate engineering approaches.

Acknowledgements. We thank Andrew Conley for helpful comments to the manuscript. Ben Kravitz is supported by the Fund for Innovative Climate and Energy Research (FICER). The Pacific Northwest National Laboratory is operated for the US Department of Energy by Battelle Memorial Institute under contract DE-AC05-76RLO 1830. Alan Robock is supported by NSF grants GEO-1240507 and AGS-1157525. Ulrike Niemeier is supported by the German Science foundations project SPP 1689 (Ceibral). Jason English is supported by NASA grant NNX09AK71G. The simulations were performed on the computers of the German Climate Computing Center (DKRZ). The CESM project is supported by the National Science Foundation and the Office of Science (BER) of the U. S. Department of Energy. The National Center for Atmospheric Research is funded by the National Science Foundation.

Edited by: F. O’Connor

\section{References}

Aquila, V., Garfinkel, C. I., Newman, P., Oman, L., and Waugh, D.: Modifications of the quasi- biennial oscillation by a geoengineering perturbation of the stratospheric aerosol layer, Geophys. Res. Lett., 41, 1738-1744, doi:10.1002/2013GL058818, 2014.

Berdahl, M., Robock, A., Ji, D., Moore, J. C., Jones, A., Kravitz, B., and Watanabe, S.: Arctic cryosphere response in the Geoengineering Model Intercomparison Project G3 and G4 scenarios, J. Geophys. Res.-Atmos., 119, 1308-1321, doi:10.1002/2013JD020627, 2014.

Curry, C. L., Sillmann, J., Bronaugh, D., Alterskjaer, K., Cole, J. N. S., Ji, D., Kravitz, B., Kristjánsson, J. E., Moore, J. C., Muri, H., Niemeier, U., Robock, A., Tilmes, S., and Yang, S.: A multimodel examination of climate extremes in an idealized geoengineering experiment, J. Geophys. Res.-Atmos., 119, 3900-3923, doi:10.1002/2013JD020648, 2014.

English, J. M., Toon, O. B., and Mills, M. J.: Microphysical simulations of sulfur burdens from stratospheric sulfur geoengineering, Atmos. Chem. Phys., 12, 4775-4793, doi:10.5194/acp-12-47752012, 2012.

Eyring, V., Lamarque, J.-F., and Hess, P.: Overview of IGAC/SPARC Chemistry-Climate Model Initiative (CCMI) Community Simulations in Support of Upcoming Ozone and Climate Assessments, Tech. rep., 2013.

Ferraro, A. J., Highwood, E. J., and Charlton-Perez, A. J.: Weakened tropical circulation and reduced precipitation in response to geoengineering, Environ. Res. Lett., 9, 014001, doi:10.1088/1748-9326/9/1/014001, 2014.

Heckendorn, P., Weisenstein, D., Fueglistaler, S., Luo, B. P., Rozanov, E., Schraner, M., Thomason, L. W., and Peter, T.: The impact of geoengineering aerosols on stratospheric temperature and ozone, Environ. Res. Lett., 4, 045108, doi:10.1088/17489326/4/4/045108, 2009.

Kokkola, H., Hommel, R., Kazil, J., Niemeier, U., Partanen, A.-I., Feichter, J., and Timmreck, C.: Aerosol microphysics modules in the framework of the ECHAM5 climate model - intercomparison under stratospheric conditions, Geosci. Model Dev., 2, 97-112, doi:10.5194/gmd-2-97-2009, 2009.

Kravitz, B., Robock, A., Boucher, O., Schmidt, H., Taylor, K. E., Stenchikov, G., and Schulz, M.: The Geoengineering Model Intercomparison Project (GeoMIP), Atmos. Sci. Lett., 12, 162167, doi:10.1002/asl.316, 2011.

Kravitz, B., Caldeira, K., Boucher, O., Robock, A., Rasch, P. J., Alterskjaer, K., Karam, D. B., Cole, J. N. S., Curry, C. L., Haywood, J. M., Irvine, P. J., Ji, D., Jones, A., Kristjánsson, J. E., Lunt, D. J., Moore, J. C., Niemeier, U., Schmidt, H., Schulz, M., Singh, B., Tilmes, S., Watanabe, S., Yang, S., and Yoon, J.-H.: Climate model response from the Geoengineering Model Intercomparison Project (GeoMIP), J. Geophys. Res.-Atmos., 118, 8320-8332, doi:10.1002/jgrd.50646, 2013a.

Kravitz, B., Robock, A., Forster, P. M., Haywood, J. M., Lawrence, M. G., and Schmidt, H.: An overview of the Geoengineering Model Intercomparison Project (GeoMIP), J. Geophys. Res.Atmos., 118, 13103-13107, doi:10.1002/2013JD020569, 2013b.

Meinshausen, M., Smith, S. J., Calvin, K., Daniel, J. S., Kainuma, M. L. T., Lamarque, J.-F., Matsumoto, K., Montzka, S. A., Raper, S. C. B., Riahi, K., Thomson, A., Velders, G. J. M., and Vuuren, D. P.: The RCP greenhouse gas concentrations and their extensions from 1765 to 2300, Climatic Change, 109, 213-241, doi:10.1007/s10584-011-0156-z, 2011.

Moore, J. C., Rinke, A., Yu, X., Ji, D., Cui, X., Li, Y., Alterskjaer, K., Kristjánsson, J. E., Muri, H., Boucher, O., Huneeus, N., Kravitz, B., Robock, A., Niemeier, U., Schulz, M., Tilmes, S., Watanabe, S., and Yang, S.: Arctic sea ice and atmospheric circulation under the GeoMIP G1 scenario, J. Geophys. Res.-Atmos., 119, 567-583, doi:10.1002/2013JD021060, 2014. 
Niemeier, U., Timmreck, C., Graf, H.-F., Kinne, S., Rast, S., and Self, S.: Initial fate of fine ash and sulfur from large volcanic eruptions, Atmos. Chem. Phys., 9, 9043-9057, doi:10.5194/acp9-9043-2009, 2009.

Niemeier, U., Schmidt, H., and Timmreck, C.: The dependency of geoengineered sulfate aerosol on the emission strategy, Atmos. Sci. Lett., 12, 189-194, doi:10.1002/as1.304, 2011.

Niemeier, U., Schmidt, H., Alterskjaer, K., and Kristjánsson, J. E.: Solar irradiance reduction via climate engineering: Impact of different techniques on the energy balance and the hydrological cycle, J. Geophys. Res.-Atmos., 118, 11905-11917, doi:10.1002/2013JD020445, 2013.

Pierce, J. R., Weisenstein, D. K., Heckendorn, P., Peter, T., and Keith, D. W.: Efficient formation of stratospheric aerosol for climate engineering by emission of condensible vapor from aircraft, Geophys. Res. Lett., 37, L18805, doi:10.1029/2010GL043975, 2010.

Pitari, G., Aquila, V., Kravitz, B., Robock, A., Watanabe, S., Cionni, I., Luca, N. D., Genova, G. D., Mancini, E., and Tilmes, S.: Stratospheric ozone response to sulfate geoengineering: Results from the Geoengineering Model Intercomparison Project (GeoMIP), J. Geophys. Res.- Atmos., 119, 2629-2653, doi:10.1002/2013JD020566, 2014.

Robock, A.: Volcanic eruptions and climate, Rev. Geophys., 38, 191-219, doi:10.1029/1998RG000054, 2000.

Roeckner, E., Bäuml, G., Bonaventura, L., Brokopf, R., Esch, M., Giorgetta, M., Hagemann, S., Kirchner, I., Kornblueh, L., Manzini, E., Rhodin, A., Schlese, U., Schulzweida, U., and Tompkins, A.: The atmospheric general circulation model ECHAM5 - Part I, Tech. Rep. 349, 2003.

Sato, M., Hansen, J. E., McCormick, M. P., and Pollack, J. B.: Stratospheric aerosol optical depths, 1850-1990, J. Geophys. Res., 98, 22987, doi:10.1029/93JD02553, 1993.

Schmidt, H., Alterskjær, K., Bou Karam, D., Boucher, O., Jones, A., Kristjánsson, J. E., Niemeier, U., Schulz, M., Aaheim, A., Benduhn, F., Lawrence, M., and Timmreck, C.: Solar irradiance reduction to counteract radiative forcing from a quadrupling of $\mathrm{CO}_{2}$ : climate responses simulated by four earth system models, Earth Syst. Dynam., 3, 63-78, doi:10.5194/esd-3-63-2012, 2012.

Special Section on GeoMIP: J. Geophys. Res., http://onlinelibrary. wiley.com/10.1002/(ISSN)2169-8996/specialsection/GEOMIP1 (last access: 12 December 2013), 2014.

Stier, P., Feichter, J., Kinne, S., Kloster, S., Vignati, E., Wilson, J., Ganzeveld, L., Tegen, I., Werner, M., Balkanski, Y., Schulz, M., Boucher, O., Minikin, A., and Petzold, A.: The aerosol-climate model ECHAM5-HAM, Atmos. Chem. Phys., 5, 1125-1156, doi:10.5194/acp-5-1125-2005, 2005.
Taylor, K. E., Stouffer, R. J., and Meehl, G. A.: An Overview of CMIP5 and the experiment design, Bull. Am. Meteorol. Soc., 93, 485-498, doi:10.1175/BAMS-D-11-00094.1, 2012.

Thompson, D. W. J., Solomon, S., Kushner, P. J., England, M. H., Grise, K. M., and Karoly, D. J.: Signatures of the Antarctic ozone hole in Southern Hemisphere surface climate change, Nat. Geosci., 4, 741-749, doi:10.1038/ngeo1296, 2011.

Tilmes, S., Garcia, R. R., Kinnison, D. E., Gettelman, A., and Rasch, P. J.: Impact of geoengineered aerosols on the troposphere and stratosphere, J. Geophys. Res., 114, D12305, doi:10.1029/2008JD011420, 2009.

Tilmes, S., Kinnison, D. E., Garcia, R. R., Salawitch, R., Canty, T., Lee-Taylor, J., Madronich, S., and Chance, K.: Impact of very short-lived halogens on stratospheric ozone abundance and UV radiation in a geo-engineered atmosphere, Atmos. Chem. Phys., 12, 10945-10955, doi:10.5194/acp-12-10945-2012, 2012.

Tilmes, S., Fasullo, J., Lamarque, J.-F., Marsh, D. R., Mills, M., Alterskjaer, K., Muri, H., Kristjánsson, J. E., Boucher, O., Schulz, M., Cole, J. N. S., Curry, C. L., Jones, A., Haywood, J., Irvine, P. J., Ji, D., Moore, J. C., Karam, D. B., Kravitz, B., Rasch, P. J., Singh, B., Yoon, J.-H., Niemeier, U., Schmidt, H., Robock, A., Yang, S., and Watanabe, S.: The hydrological impact of geoengineering in the Geoengineering Model Intercomparison Project (GeoMIP), J. Geophys. Res.-Atmos/, 118, 11036-11058, doi:10.1002/jgrd.50868, 2013.

Toohey, M., Krüger, K., Niemeier, U., and Timmreck, C.: The influence of eruption season on the global aerosol evolution and radiative impact of tropical volcanic eruptions, Atmos. Chem. Phys., 11, 12351-12367, doi:10.5194/acp-11-12351-2011, 2011.

Trepte, C. R. and Hitchman, M. H., Tropical stratospheric circulation deduced from satellite aerosol data, Nature, 355, 626-628, doi:10.1038/355626a0, 1992.

Vignati, E.:M7: An efficient size-resolved aerosol microphysics module for large-scale aerosol transport models, J. Geophys. Res., 109, D22202, doi:10.1029/2003JD004485, 2004.

Xia, L., Robock, A., Cole, J., Curry, C. L., Ji, D., Jones, A., Kravitz, B., Moore, J. C., Muri, H., Niemeier, U., Singh, B., Tilmes, S., Watanabe, S., and Yoon, J.-H.: Solar Radiation Management Impacts on Agriculture in China: A Case Study in the Geoengineering Model Intercomparison Project (GeoMIP), J. Geophys. Res.Atmos., 119, 8695-8711, doi:10.1002/2013JD020630, 2014. 